\title{
THE DEVELOPMENT OF TOP 200 PRESCRIBED DRUGS IN COMMUNITY PHARMACIES AT MEDAN CITY AS A LEARNING TOOLS
}

\section{HARI RONALDO TANJUNG*, EMBUN SUCI NASUTION}

Department of Pharmacology and Toxicology, Faculty of Pharmacy, University of Sumatera Utara, Jl. Tridharma No.5, Kampus USU Medan 20155, Indonesia. Email: harri@usu.ac.id

Received: 01 December 2016, Revised and Accepted: 29 December 2016

\section{ABSTRACT}

Objective: The pharmacy student at clerk-ship level and pharmacists need the drug information literature contains information of prescribed drug that utilized in pharmaceutical practice daily to learn effectively. The aims of the study were to develop top 200 prescribed drugs in community pharmacies at Medan city as learning tools for the pharmacy students at clerk-ship level and pharmacists.

Methods: The study was a descriptive study that used a cross-sectional survey methodology. The top 200 items of prescribed drugs obtained from the pharmacies selected regarding to random sampling method. The study was conducted from August to November 2016 . The top 200 prescribed drugs lists were developed into a draft of drug information book and a group of pharmacy students at clerk-ship level and pharmacists was asked to evaluate the book and gave suggestions using a set of questionnaire.

Results: The top 200 prescribed drugs list revealed that the five most prescribed drugs were amoxicillin (5.55\%), followed by dexamethasone (4.44\%), mefenamic acid (3.73\%), cetirizine (3.16\%), and ciprofloxacin (2.97\%). The result of a draft of drugs information book evaluation that was evaluated by 120 pharmacy students and pharmacists showed the drug information book draft was good and able to publish. The respondents mention some suggestion for the book, i.e., "image made more attractive and in various colors and the image adjusted with an indication of drug" (43.74\%) and "using language that is easily understood and more detailed information" (16.85\%).

Conclusions: The study has developed top 200 prescribed drugs in community pharmacies at Medan city into a validated drug information book as a learning tool. The drug information book very useful for a continuing professional development program for pharmacists and build the pharmacy student's confidence before they face the real patients at the community pharmacy practice setting.

Keywords: Prescribed drugs, Drug information, Learning tools.

(c) 2017 The Authors. Published by Innovare Academic Sciences Pvt Ltd. This is an open access article under the CC BY license (http://creativecommons. org/licenses/by/4. 0/) DOI: http://dx.doi.org/10.22159/ajpcr.2017.v10i4.16434

\section{INTRODUCTION}

The pharmaceutical care concept practice was encouraged pharmacy practice around the world. The pharmacist role was extended not only just responsible for product oriented but also to identify, manage and prevent the patient's drug-related problems [1,2]. Furthermore, the pharmacy education in the world has been evolved to adopt the pharmaceutical care concepts. A pharmacy student required to learn more on knowledge and clinical skills, i.e., pharmacology, pharmacotherapy, clinical pharmacy, drug management, psychology and communication, health promotion, and diseases prevention. The pharmacy student must also possess prescribed drug knowledge to practice the pharmaceutical care services in community pharmacy setting $[3,4]$.

The drug information literature contains thousands of drugs, which much of them were rare or never prescribed by the physicians. It caused pharmacy students must learn thousands of drugs that will deplete resources, and the study result was not effective. This condition revealed that the pharmacy student and pharmacist need the drug information literature contains information of prescribed drug that utilized in pharmaceutical practice daily. The pharmacy students and pharmacists will able to learn effectively by the availability of this drug information literature.

Some countries have been evolved the top 200 prescribed drugs mostly prescribed and have been evaluated to the list continuously [5-7]. A university in the US also obligated the second and third year pharmacy student to pass a 50-multiple choice examination of the top 200 most frequently prescribed drug. The test was done to ensure the pharmacy students have developed the knowledge base as the requirement to the later courses [8]. Therefore, the top 200 prescribed drugs were considered as a list that must learn by pharmacy students to practice the pharmaceutical care services effectively.

Lately, the list of top 200 prescribed drugs that available was based on drug utilization in foreign countries and the list was not appropriate with the drugs utilization in Indonesia. The study aims to develop the drugs list of 200 items of prescribed drugs in community pharmacies at Medan city into a drug information literature.

\section{METHODS}

This study was a descriptive research that used a cross-sectional survey methodology. The 200 prescribed drugs list obtained from the physician's prescription retrospectively by direct survey to the selected community pharmacy at Medan city. The selection of community pharmacy was done by random sampling method. The study was conducted on August to October 2016.

Based on the health department of Medan city data, there are 617 (N) pharmacies at Medan city. The number of sample (n) was calculated by Slovin formula: $n=N /\left(1+\mathrm{N}^{2}\right)$ [9]. The study used 0.1 as error tolerance (e) and it was obtained 86 pharmacies as a minimum sample amount. The researcher added the sample amount to 100 pharmacies. The selected pharmacies located at 16 district area of 21 district area of Medan city.

The study excluded nonprescribed drugs, vitamin and mineral supplements, vaccines and antiserum, biopharmaceuticals and 
immunoglobulin from the list. The 200 drug lists were grouped and categorized with the Anatomical Therapeutic Chemical (ATC) classification system that recommended by the WHO for drug utilization studies [10]. The top 200 prescribed drugs lists were developed into a draft of drug information book and a group of pharmacy students at clerk-ship level and pharmacists (120 respondents) was asked to evaluate the book and gave suggestions using a set of questionnaire.

\section{RESULTS}

\section{Top 200 prescribed drugs}

The 200 items of prescribed drugs resulted from 21.962 prescribed drugs item of 16.352 prescriptions of 100 pharmacies.

The five most prescribed drugs were amoxicillin (5.55\%), followed by dexamethasone $(4.44 \%)$, mefenamic acid $(3.73 \%)$, cetirizine $(3.16 \%)$, and ciprofloxacin $(2.97 \%)$ as mention in Table 1 . The study categorized prescribed drugs by ATC classification system as shown in Table 2.

Table 2 revealed the five most frequently drugs prescribed by physician in pharmacies based on therapeutic class was antibacterial (24.60\%), anti-inflammatory and antirheumatic (10.13\%), corticosteroids (9.49\%), antihistamines (6.39\%), and psycholeptics (5.62\%). It shown that antibacterial was the most frequently prescribed drug with the percentage of utilization as much as $24.60 \%$. The five most antibacterial drugs prescribed by the physician were amoxicillin

Table 1: Top 10 of 200 prescribed drugs in community pharmacies

\begin{tabular}{lll}
\hline No. & Drugs name & Percentage \\
\hline 1 & Amoxicillin & 5.55 \\
2 & Dexamethasone & 4.44 \\
3 & Mefenamic acid & 3.73 \\
4 & Cetirizine & 3.16 \\
5 & Ciprofloxacin & 2.97 \\
6 & Cefadroxil & 2.83 \\
7 & Salbutamol & 2.71 \\
8 & Diazepam & 2.69 \\
9 & Domperidone & 2.57 \\
10 & Cefixime & 2.19 \\
\hline $\mathrm{n}=21.962$. & The complete list available with permit of corresponding author
\end{tabular}

Table 2: The top 5 prescribed drugs utilization by therapeutic class

\begin{tabular}{lll}
\hline No. & Therapeutic class & Percentage \\
\hline 1 & Antibacterial & 24.60 \\
2 & Anti-inflammatory and antirheumatic & 10.13 \\
3 & Corticosteroids & 9.49 \\
4 & Antihistamines & 6.39 \\
5 & Psycholeptics & 5.62 \\
\hline $\mathrm{n}=21.962$ & &
\end{tabular}

(5.55\%), ciprofloxacin (2.97), cefadroxil (2.83\%), cefixime $(2.19 \%)$, and levofloxacin $(2.11 \%)$.

The development of top 200 prescribed drugs lists as learning tools A draft of drug information book was developed from the top 200 prescribed drugs lists. The book was arranged based on number of prescription from the highest to the lowest and the drug information was consist of generic name of the drugs, trade mark names, therapeutic class, indication, mechanism of action, dose, adverse effect, contraindication, drug interaction, administration suggestions, and important information for patients related the drugs. A group of pharmacy students at clerk-ship level and pharmacists (120 respondents) was asked to evaluate the book and gave suggestions using a set of questionnaire (Table 3)

The evaluation result of a draft of drugs information book was good for overall and all respondents agree the book could be used as learning tools to most prescribed drugs in community pharmacies setting. The respondents gave the highest rate (3.57) for "The information on medicines that are closely related to the daily practice of pharmacy" and the lowest rate (2.15) for "the suitability of the illustrations in the form of the displayed image (Table 4)."

The respondents groups also asked to give the suggestion for the book. The result showed that of 110 suggestions, 43.74\% suggestions was "image made more attractive and in various colors and the image adjusted with an indication of drug" followed by "using language that is easily understood and more detailed information."

\section{DISCUSSION}

The list of top 200 prescribed drug obtained from this research revealed that the list has huge differences with the list that published recently at the United States [11]. Levothyroxine stated as the most utilized drug followed by rosuvastatin, esomeprazole, salbutamol, and fluticasone propionate in the US list. Another drug utilization study in India also showed different result with this study result. The study stated aceclofenac as the most utilized nonsteroidal anti-inflammatory drugs (NSAIDs) [12]. Meanwhile, this study revealed mefenamic acid as the most utilized NSAIDs. It showed that the drug utilization lists at foreign country were not similar and not suitable with the local drug utilization. As a conclusion, to develop a drug list as a learning tool, it is more appropriate to use a local drugs utilization data.

Table 2 revealed antibacterial class drug as the most frequently prescribed drug $(24.60 \%)$ by the physicians. Another study at different setting area also revealed antibacterial as the most frequently prescribed drugs (36.02\%) [13]. In our study, the five most antibacterial drugs prescribed by the physician at community pharmacies were amoxicillin (5.55\%), ciprofloxacin (2.97), cefadroxil (2.83\%), cefixime $(2.19 \%)$, and levofloxacin $(2.11 \%)$. This antibacterial utilization $(24.60 \%)$ was much higher than antibacterial utilization (7\%) at UK [2]. The high utilization of antibacterial has brings significant implications. The use of antibacterial drugs at community pharmacy setting usually was done

Table 3: The result of draft of drug information book evaluation

\begin{tabular}{|c|c|c|c|}
\hline No. & Parameters & Mean \pm SD & Category \\
\hline 1 & The use of easily understood language & $3.00 \pm 0.81$ & Good \\
\hline 2 & The use of images in accordance with contents & $2.16 \pm 0.80$ & Fair \\
\hline 3 & Colors and images selected was interesting for users & $2.40 \pm 0.88$ & Fair \\
\hline 4 & The type and size of the letters used in appropriate way & $3.17 \pm 0.74$ & Good \\
\hline 5 & The drug information is easy to understand & $3.21 \pm 0.79$ & Good \\
\hline 6 & Suitability and appropriateness of the placement of the elements layout (topics, subtopics, and illustrations) & $3.12 \pm 0.69$ & Good \\
\hline 7 & The submission of information simple and easy to understand & $2.96 \pm 0.86$ & Fair \\
\hline 8 & The submission of information is interactive and motivating students to learn independently & $3.08 \pm 0.74$ & Good \\
\hline 9 & The suitability of the illustrations in the form of the displayed image & $2.15 \pm 1.00$ & Fair \\
\hline 10 & The accuracy of content & $3.25 \pm 0.66$ & Good \\
\hline 11 & The information on medicines that are closely related to the daily practice of pharmacy & $3.57 \pm 0.59$ & Good \\
\hline
\end{tabular}

Score: 1 (not good), 2 (fair), 3 (good), 4 (very good). n=120. SD: Standard deviation 
Table 4: Suggestion from the respondent group

\begin{tabular}{|c|c|c|}
\hline No. & Suggestions & Percentage \\
\hline 1 & $\begin{array}{l}\text { Image made more attractive and in various } \\
\text { colors and the image adjusted with an } \\
\text { indication of drug }\end{array}$ & 43.74 \\
\hline 2 & $\begin{array}{l}\text { The use of language that is easily understood } \\
\text { and more detailed information }\end{array}$ & 16.85 \\
\hline 3 & $\begin{array}{l}\text { The color selection can be varied according } \\
\text { pharmacological effects or subtopics }\end{array}$ & 12.36 \\
\hline 4 & $\begin{array}{l}\text { Easily understood language, the language } \\
\text { used uniforms and symbols created in color }\end{array}$ & 5.65 \\
\hline 5 & Stated the price of each drug (in range) & 4.49 \\
\hline 6 & $\begin{array}{l}\text { The working mechanism created with } \\
\text { illustrations }\end{array}$ & 3.76 \\
\hline 7 & The use of abbreviations explained & 3.04 \\
\hline 8 & Drug names grouped by therapeutic class & 2.25 \\
\hline 9 & $\begin{array}{l}\text { Made with different colors for one class of } \\
\text { therapy }\end{array}$ & 2.25 \\
\hline 10 & $\begin{array}{l}\text { Put the drug packaging illustration on the } \\
\text { market }\end{array}$ & 2.25 \\
\hline 11 & Stated much more number of trade mark & 1.12 \\
\hline 12 & $\begin{array}{l}\text { Recommended to create a structured dose at } \\
\text { the dose part }\end{array}$ & 1.12 \\
\hline 13 & $\begin{array}{l}\text { The drug mechanism of action should be put } \\
\text { before the drug interaction part }\end{array}$ & 1.12 \\
\hline
\end{tabular}

by empirical method. The physician was choose the kind of antibacterial based on empirical experience and literature review, not based on microbiological culture test. This circumstance will increase the risk of resistance event on antibacterial utilization. The utilization of some antibacterial also needs to determine whether they were prescribed appropriately or not [12,14-16]. Furthermore, another study in Indonesia also revealed antibacterial class as one of three medication class that mostly caused unnecessary drug therapy incidents related to the increasing costs of drug therapy [17]. The high utilization and costly forms of antibacterial are needs to be regulated and supervised closely.

The pharmacy students and pharmacists will able to learn the drug information effectively using the list because they just focus on the most prescribed drugs that really utilized daily in the community pharmacy setting. The drug lists were very useful for a continuing professional development program for pharmacists and build the pharmacy student's confidence before they face the real patients at the community pharmacy practice setting $[3,8]$.

Overall, the respondents groups agreed that the drug information book could be used to possess the knowledge of prescribed drug effectively by the pharmacy students and pharmacists. The respondents also added some suggestion that very important to make the book become more easy to read and understand by the user. The most frequently suggestion stated by respondents was "Image made more attractive and in various colors and the image adjusted with an indication of drug." This suggestion was suitable with the result of evaluation that stated the lowest rate $(2.15 \pm 1.00)$ for the "the suitability of the illustrations in the form of the displayed image". It means that the respondents considered the existing of "suitable image or illustration" very important to enhance the reader's understanding especially in mechanism of action part. Another study also mentions to produce the list with high-quality color paper and added the index and picture of products to make it noticeable and easily accessible [3]. The next important suggestion from the respondents was "the use of language that is easily understood and more detailed information." Since the draft of drug information book was intended to make it simple, so the use of many medicine or health terms was inevitable. The authors had put a list of definition of important terms at the end of the book to help the book's user.

The pharmacy students, academics staff or pharmacists will get benefit from this list, but they must remember that different areas have different prescribing patterns. Another study also stated that the list should be updated in two years to make the lists always up to date with the daily practice of community pharmacy setting [3].

\section{CONCLUSIONS}

The study has developed top 200 prescribed drugs in community pharmacies at Medan city into a validated drug information book as a learning tool. The drug information book very useful for a continuing professional development program for pharmacists and build the pharmacy student's confidence before they face the real patients at the community pharmacy practice setting.

\section{ACKNOWLEDGMENT}

The authors acknowledge that the research was supported by Rector of the University of Sumatera Utara. The support is under the research grant TALENTA USU of year 2016 contract number 69/UN5.2.3.1/PPM/ SP/2016.

\section{REFERENCES}

1. Cipolle RJ, Strand LM, Morley PC. Pharmaceutical Care Practice: The Clinician's Guide. Ch. 7. New York: McGraw-Hills; 2004.

2. American Society of Hospital Pharmacists. ASHP statement on pharmaceutical care. Am J Hosp Pharm 1993;50:1720-3.

3. Winit-Watjana W, Francis D, Ho HM. Top 200 prescribed drugs as a tool for pharmacy teaching and training. Pharm Educ 2011;11(1):46-53.

4. Jisha ML, Minaz N. Understanding the pharmaceutical care concept: A review. Int Res J Pharm 2011;2(9):12-4.

5. Silverman HM. The Pill Book. New York: Bantam; 2008.

6. Lamb E. Top 200 Prescription Drugs of 2006. Pharmacy Times. 2007. p. 34-7.

7. Evans C, Foushee L, Al-Achi A. Top 200 prescribed drugs learning tool and objective evaluation instruments in community pharmacy clerkship sites. J Am Pharm Assoc 2006;46(2):292-3.

8. Santee J. A web-based practice examination to improve student performance concerning the 200 most prescribed drugs. Am J Pharm Educ 2003;67(4):102.

9. Umar H. Research Methods for Skripsi and Business Thesis. Jakarta: PT Raja Grafindo SSPersada; 2004.

10. WHO. Guidelines for ATC Classification and DDD Assignment. Geneva: WHO; 2013.

11. Brooks M. Top 100 Most Prescribed Top-Selling Drugs. Available from: http://www.medscape/viewarticle/829246. [Last retrieved on 2016 Oct 10].

12. Alam N, Bhardwaj A, Tiwari R, Sharma S, Dabas V. Drug utilization pattern of patients using NSAIDs in South Delhi Hospital. Int J Pharm Pharm Sci 2012;4 Suppl 3:703-7.

13. Jyothi K, Jagadish Babu D. Drug utilization evaluation of Cephalosporin in general medicine units of rural tertiary care hospital. Int J Curr Pharm Res 2012;4(2):88-91.

14. Desalegn AA. Assessment of drug use pattern using WHO prescribing indicators at Hawassa University Teaching and Referral Hospital, south Ethiopia: A cross-sectional study. BMC Health Serv Res 2013;13:170.

15. Ministry of Health of Republic Indonesia. The Law of Republic Indonesia Ministry of Health No. HK. 02/Menkes/068/I/2010.

16. de Vries TP, Henning RH, Hogerzeil HV, Fresle DA. Guide to Good Prescribing: A Practical Manual. Geneva: The World Health Organization, (Original Work Published 1994); 2000.

17. Fita R, Dewa PP, Wasilah R, Azhar SS. Polypharmacy and unnecessary drug therapy on geriatric hospitalized patients in Yogyakarta Hospitals, Indonesia. Int J Pharm Pharm Sci 2009;1 Suppl 1:6-11. 